\title{
Analisis Personal Branding Selebgram Nonselebriti Akun Instagram @Lippielust
}

\author{
Dita Rachmawati ${ }^{1}$ dan Dini Salmiyah Fithrah Ali ${ }^{2}$
}

\author{
${ }^{1,2}$ Universitas Telkom \\ Jl. Telekomunikasi No. 1, Terusan Buah Batu, Bandung 40257 \\ Ifaladita@yahoo.co.id, ${ }^{2}$ dinidjohan@gmail.com
}

\begin{abstract}
Social media nowadays has become tool of marketing and promotion of goods, services, and personal like Instagram. Being a celebgram should have a strong personal pranding, has uniqueness, the difference from other celebgram in order to have a long existence to be celebgram on social media Instagram. Rissa is a noncelebrity celebgram. Rissa's known as an endorser for beauty project this leap how to work together on a project professional with many brands in the country and abroad. Rissa became a celebgram with a very specific focus that is more beauty that leads to lipstick. This study discusses about how Personal Branding criteria non celebrity celebgram. The method used is descriptive qualitative with indicator 11 Authentic Personal Branding criterion according to Rampersad. In this study, Rissa's Personal Branding has a personality as which is character, values, vision that suits personal ambition, moral code and behavior, consistent, focused on one field, acknowledged and experienced, unique, connected to the audience, owns good relationship with partnerwork and always make self improvement in Instagram account @ lippielust.
\end{abstract}

Keywords: Personal Branding, Social Media, Instagram, Celebgram, Rissa Stellar

\begin{abstract}
Abstrak
Media sosial saat ini telah menjadi sarana dalam melakukan pemasaran maupun promosi baik barang, jasa, maupun personal khususnya salah satunya adalah Instagram. Untuk menjadi seorang selebgram dibutuhkan personal branding yang kuat, memiliki kekhasan, dan berbeda dari selebgram lainnya agar mempunyai eksistensi dan bertahan lama sebagai seorang selebgram di media sosial Instagram. Rissa merupakan seorang selebgram bukan selebriti, yang disebut selebgram nonselebriti. Personal Branding yang dilakukan Rissa menjadikannya sebagai endorser dan berhasil bekerja sama secara project professional dengan banyak brand dalam negeri maupun luar negeri. Rissa menjadi selebgram dengan fokus spesifik yaitu beauty yang lebih mengarah kepada lipstick. Penelitian ini membahas bagaimana kriteria Personal Branding selebgram nonselebriti. Metode yang digunakan adalah deskriptif kualitatif dengan indikator 11 kriteria Authentic Personal Branding menurut Rampersad. Hasil penelitian ini, Personal Branding yang dilakukan Rissa memiliki kepribadian yang memiliki karakter, nilai-nilai, visi yang sesuai dengan ambisi pribadi, kode moral dan perilaku, konsisten, berfokus pada satu bidang, diakui dan berpengalaman, unik, terhubung dengan khalayak, memiliki hubungan yang baik dengan partner pekerjaan, dan selalu melakukan perbaikan diri dalam akun Instagram @lippielust.
\end{abstract}

Kata Kunci: Personal Branding, Media Sosial, Instagram, Selebgram, Rissa Stellar

Copyright $\odot 2018$ Ikatan Sarjana Komunikasi Indonesia. All rights reserved

\section{PENDAHULUAN}

Tren yang sedang berkembang sekarang ini dalam platform Instagram, sebuah perusahaan atau penjual dapat menjual dana tau mempromosikan produknya lewat profil mereka sendiri atau melalui orang lain. Dimana perusahaan bisa mempromosikan produknya lewat profil pengguna dengan followers yang banyak yang dapat meluaskan cakupan produknya dengan orang yang terpercaya pada dunia maya tersebut. Biasanya penjual atau perusahaan meminta jasa promosi kepada orang yang memiliki Personal Branding yang sesuai dengan klasifikasi penjual/perusahaan. Branding tidak hanya untuk perusahan, tetapi sekarang ada tren baru yang biasa disebut dengan Personal Branding. Dalam Personal Branding, 
seseorang membentuk branding tersendiri untuk akun sosial medianya. Untuk menegaskan citra mereka di dalam akun sosial media tersebut.

Montoya (2002) menyatakan Personal Branding sebagai proses strategi tentang sengaja mengendalikan bagaimana orang lain memandang diri dan mengelola persepsi tersebut secara strategis untuk membantu untuk mencapai tujuan yang telah direncanakan sebelumnya.

Masyarakat Indonesia suka berselancar di dunia maya. Instagram kini berada di urutan ketiga penggunaan terbanyak di Indonesia. Sekarang pada sosial media Instagram terdapat sebuah tren yang dimana disebut selebgram. Selebgram diidentifikasi sebagai artisnya dunia maya Instagram yang merupakan berasal dari noncelebrity, tetapi mereka terkenal di platform tersebut. Selebgram telah menjadi tren, setara dengan selebriti dengan hanya menggunakan platform Instagram. Sekarang ini para selebgram terdiri dari bermacam-macam, misalnya tentang kecantikan, pecinta makanan, komedian, pecinta travelling dan lain-lain yang saling memamerkan konten mereka masing masing pada profilnya.

Untuk membedakan dari yang lainnya dan agar terlihat lebih menonjol, selebgram harus memiliki perbedaan tersendiri agar lebih dikenal oleh orang lain maupun sebagai alat untuk mendapatkan profit dari konten media sosial Instagram. Untuk membentuk Personal Branding, para selebgram akan membentuk feeds mereka agar lebih menarik dilihat oleh pengguna lainnya pada platform tersebut. Untuk menjadi selebgram, Personal Branding adalah hal yang sangat penting.

Rissa Stellar, seorang selebgram, memiliki hal yang unik. Dalam akun Instagramnya yang bernama @lippielust, Rissa membranding dirinya sebagai selebgram beauty influencer khususnya pada bagian bibirnya. Rissa sendiri merupakan selebgram nonselebriti. Rissa dikenal sebagai selebgram beauty influencer yang biasanya memposting tentang dirinya sebagai content creator dan lipstick swatcher.

Selain itu, Rissa dijuluki sebagai the queen of lipstick swatches, yang buktikan dengan banyaknya brand yang sudah bekerja sama. Beberapa post Instagram @lippielust ada yang di-regram langsung oleh brand internasional seperti Stila, Girlactic, dan Tarte. Selain dari brand internasional, Rissa banyak di endorse dan didaulat untuk men-swatch lipstick untuk brand ternama tanah air, salah satunya seperti Make Over Cosmetics. Rissa juga berkolaborasi dengan brand evt meluncurkan produk lip remedies by @ lippielust.

Media sosial Instagram sebagai wadah pengekspresian diri dengan cara Personal Branding. Termasuk Rissa yang menjadikan Instagram sebagai wadah untuk pengekspresian dirinya di dunia maya dengan cara mengunggah konten-konten tertentu pada akun Instagramnya. Terlihat dari konten-konten yang diunggah Rissa di Instagram lebih cenderung tentang makeup yang ditampilkan.

Rissa Stellar merupakan selebgram yang bukan berasal dari selebritas dengan spesifikasi beauty yang lebih mengarah kepada lipstick dan merupakan Indonesia's ultimate source for swatches and reviews.

Penelitian ini ingin mengetahui unsur apa saja yang menjadikan Rissa dipilih oleh para brand untuk memasarkan produk mereka. Berdasarkan uraian dari latar belakang di atas, penulis tertarik untuk menganalisis bagaimana kriteria Personal Branding selebgram nonselebriti melalui akun media sosial Instagram @ lippielust yang dilakukan oleh Rissa Stellar?

\section{KERANGKA TEORITIS}

Everet M. Rogers dalam Mulyana (2008: 69) menyebutkan bahwa komunikasi itu proses ide seseorang yang dialihkan dari seorang sumber terhadap orang lain atau lebih dengan tujuan untuk mengubah tingkah laku. Carl I. Hovland (Mulyana 2008: 68) mendefinisikan bahwa komunikasi merupakan proses dimana komunikator menyampaikan suatu rangsangan kepada komunikan biasanya dengan suatu lambang dalam bentuk verbal, dengan tujuan mengubah perilaku komunikan.

Sementara itu sesuai kemajuan zaman, saat ini new media merupakan hal yang sangat penting sebagai akibat perkembangan dan kemajuan teknologi informasi. Media dikenal khalayak sebagai pengkoordinasi suatu informasi dalam berbagai bentuk. Castells (dalam Gane \& Beer, 2008: 8) menyebut 
new media sebagai kekuatan yang memacu munculnya jejaring sosial yang di dominasi dan pusatnya pada suatu khalayak.

Nasrullah (2015:11) mengatakan, media sosial merupakan wadah untuk berekspresi diri di internet, berinteraksi antar pengguna, berbagi informasi dan membentuk hubungan sosial secara virtual. Software dan media sosial adalah alat untuk meningkatkan kemampuan dari pengguna itu sendiri untuk bekerja sama, berbagi diantara pengguna lainnya dan melakukan tindakan sendiri yang semuanya berada di luar kerangka organisasi maupun instusional.

Dikutip dari www.dumetdevelopment.com, nama Instagram berasal dari dua kata, yaitu "Insta" dan "Gram". Arti dari kata awal diambil dari istilah "Instan" atau serba cepat dan mudah. Tetapi, dalam sejarah penggunaan kamera foto, istilah "Instan" adalah sebutan lain dari kamera Polaroid, adalah jenis kamera yang bisa langsung mencetak foto beberapa saat setelah membidik objek. Arti kedua kata "Gram" diambil dari "Telegram" yang mempunyai makna terkait sebagai media pengirim informasi yang sangat cepat. Suryani (2013:170-171) mengatakan, penggunaan selebritis dalam mempromosikan suatu produk dapat memberikan pengaruh yang cukup kuat karena selebritis mempunyai popularitas di mata khalayak. Seorang selebriti mempunyai pengaruh dalam masyarakat dan dapat mempengaruhi konsumen lain, sementara David Aaker (2014) menyebut brand lebih dari sekedar nama dan logo. Brand memberikan sesuatu yang lebih daripada prinsip tersebut, termasuk manfaat sosial, ekspresi diri, emosional dan juga fungsional.

Personal Branding adalah proses pemisahan diri dari sekumpulan orang dengan mengidentitikasi kelebihan dari diri sendiri. Lalu menggunakan platform melalui gambar dan pesan untuk menghasilkan tujuan tertentu. Dengan Personal Branding seseorang bisa membangun reputasi, kepercayaan diri, mendorong karir sesuai dengan bidangnya sebagaimana dinyatakan Schawbel (2009) dalam Salpeter dalam buku Social Networking for Career Succes.

Peter Montoya (2005) dan Rampersad (2007:19-20) mengungkapkan kriteria-kriteria membangun Personal Branding yang efektif, meliputi (1) Keotentikan (Authenticity). Mencerminkan diri sendiri sesuai dengan visi, nilai-nilai, karakter yang dimiliki sendiri yang diselaraskan dengan ambisi pribadi; (2) Integritas (Integrity). Melaksanakan kode moral perilaku yang ditetapkan oleh ambisi pribadi; (3) Konsisten (Consistency); (4) Spesialisasi (Specialization). Fokus pada satu bidang terspesialisasi yang unik; (5) Wibawa (Authority); (6) Keberbedaan (Differentiation); (7) Relevan (Relevan); (8) Visibilitas (Visibility). Personal Branding yang dilakukan harus diulang secara terus menerus sehingga dapat tertanam di benak khalayak; (9) Kegigihan (Persistence). Satu merek yang dibangun memerlukan waktu untuk tumbuh. Harus bersabar, konsisten, jangan menyerah dan percaya terhadap diri sendiri; (10) Kebaikan (Goodwill). Personal brand akan menghasilkan hasil yang bertahan lama dan baik jika itu positif. Personal brand yang dibuat harus berkaitan dengan hal yang positif dan bermanfaat. Orang-orang berbisnis dengan apa yang mereka sukai; (11) Kinerja (Performance).

\section{METODE PENELITIAN}

Penelitian ini adalah penelitian kualitatif. Data diperoleh melalui wawancara, observasi, dokumentasi dan kajian literatur. Penelitian ini berangkat dari kasus tertentu yang ada pada situasi sosial yang tertentu juga sehingga hasil dari kajiannya tidak akan diberlakukan pada populasi, tetapi ditransferkan ke tempat lain pada situasi sosial pada kasus yang dipelajari. (Sugiyono, 2011: 216).

\section{HASIL PENELITIAN}

Kriteria Personal Branding yang dilakukan oleh akun Instagram @ lippielust untuk dianaliasi ada 11 kriteria Authentic Personal Branding menurut Rampersad sebagaimana terlihat pada tabel 1.

Tabel 1 Unit Analisis

\begin{tabular}{|l|l|l|}
\hline Variabel & Sub Variabel & Indikator \\
\hline
\end{tabular}




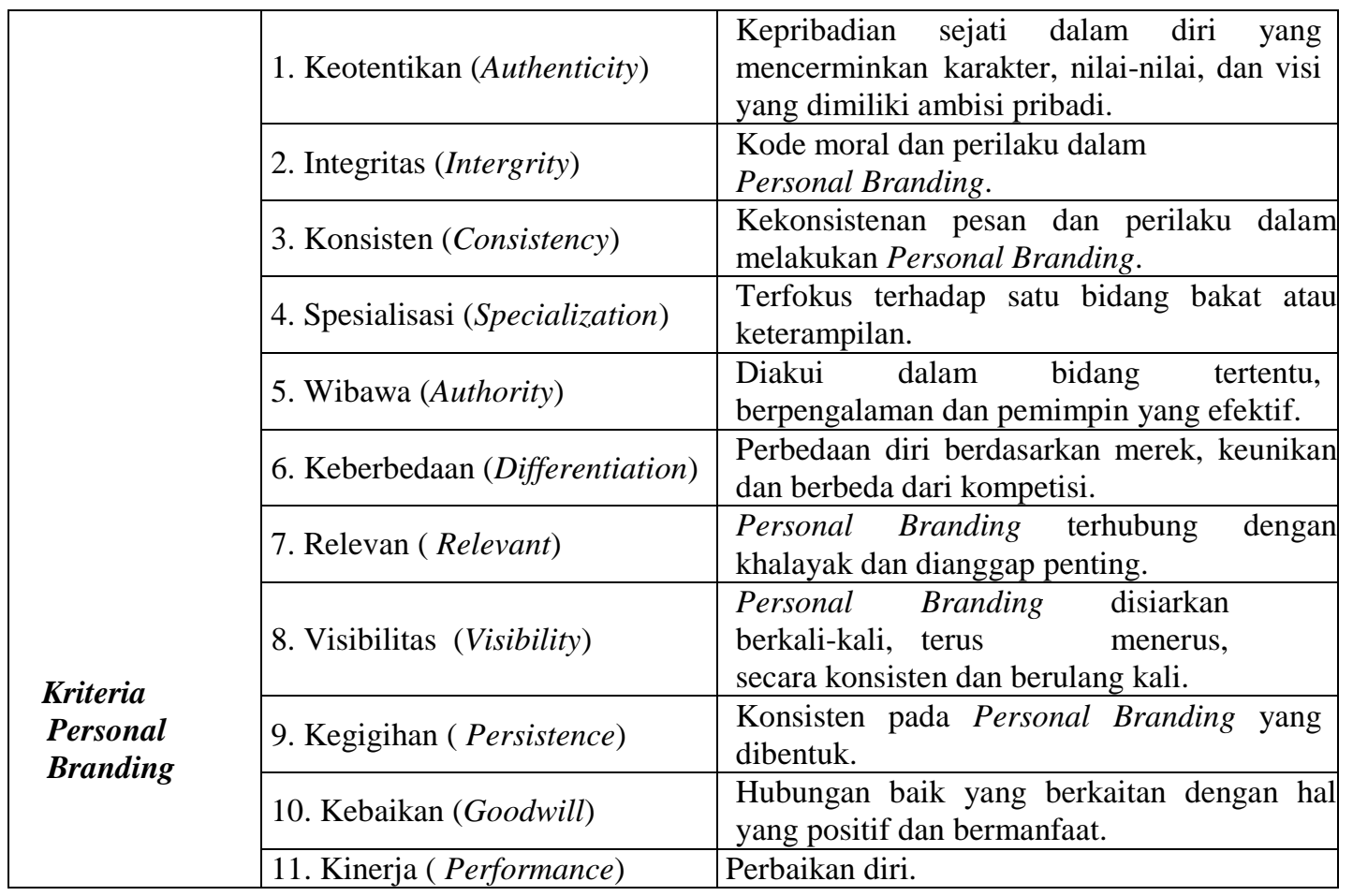

\section{Tabel 2 Hasil Wawancara}

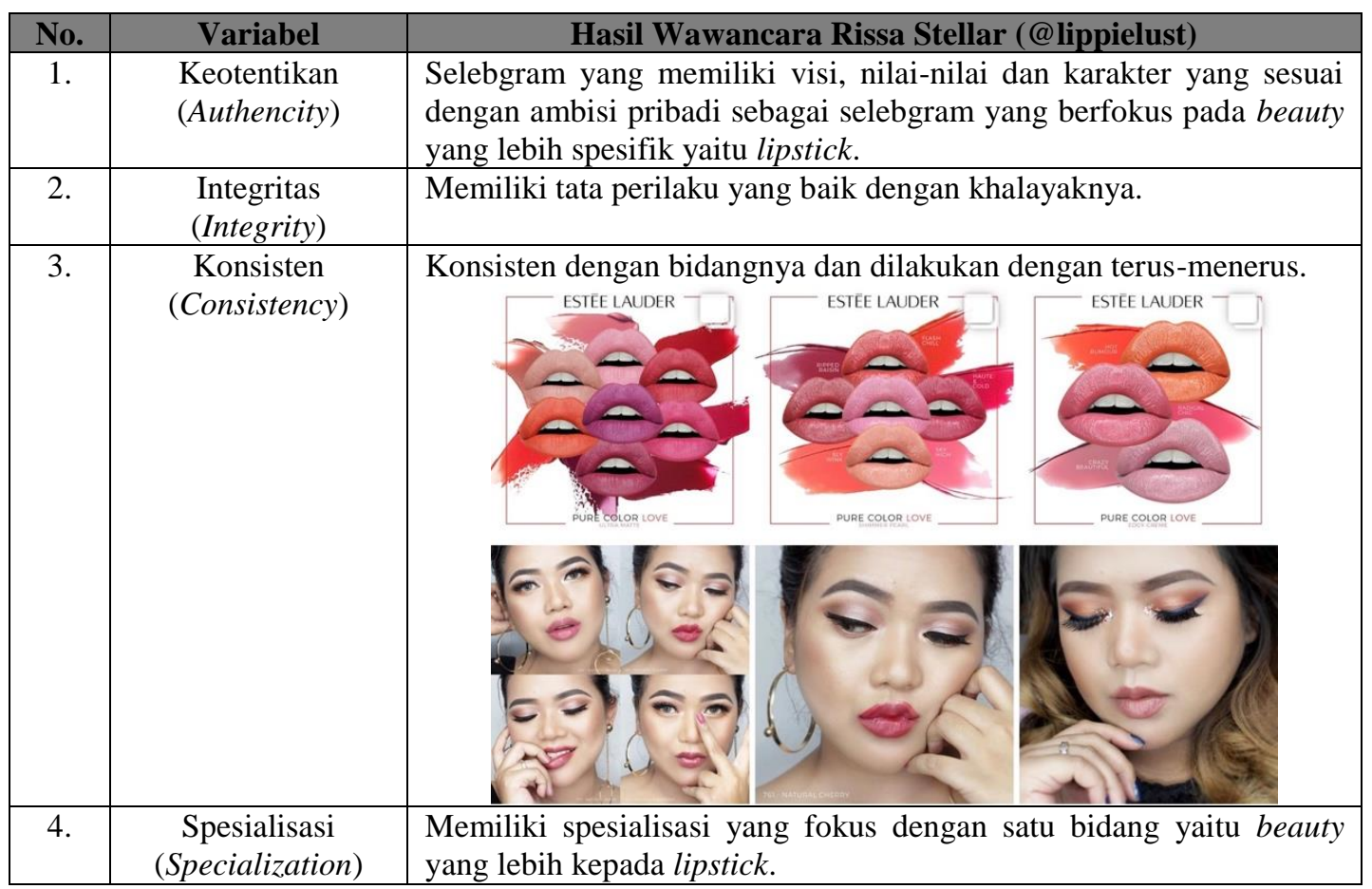




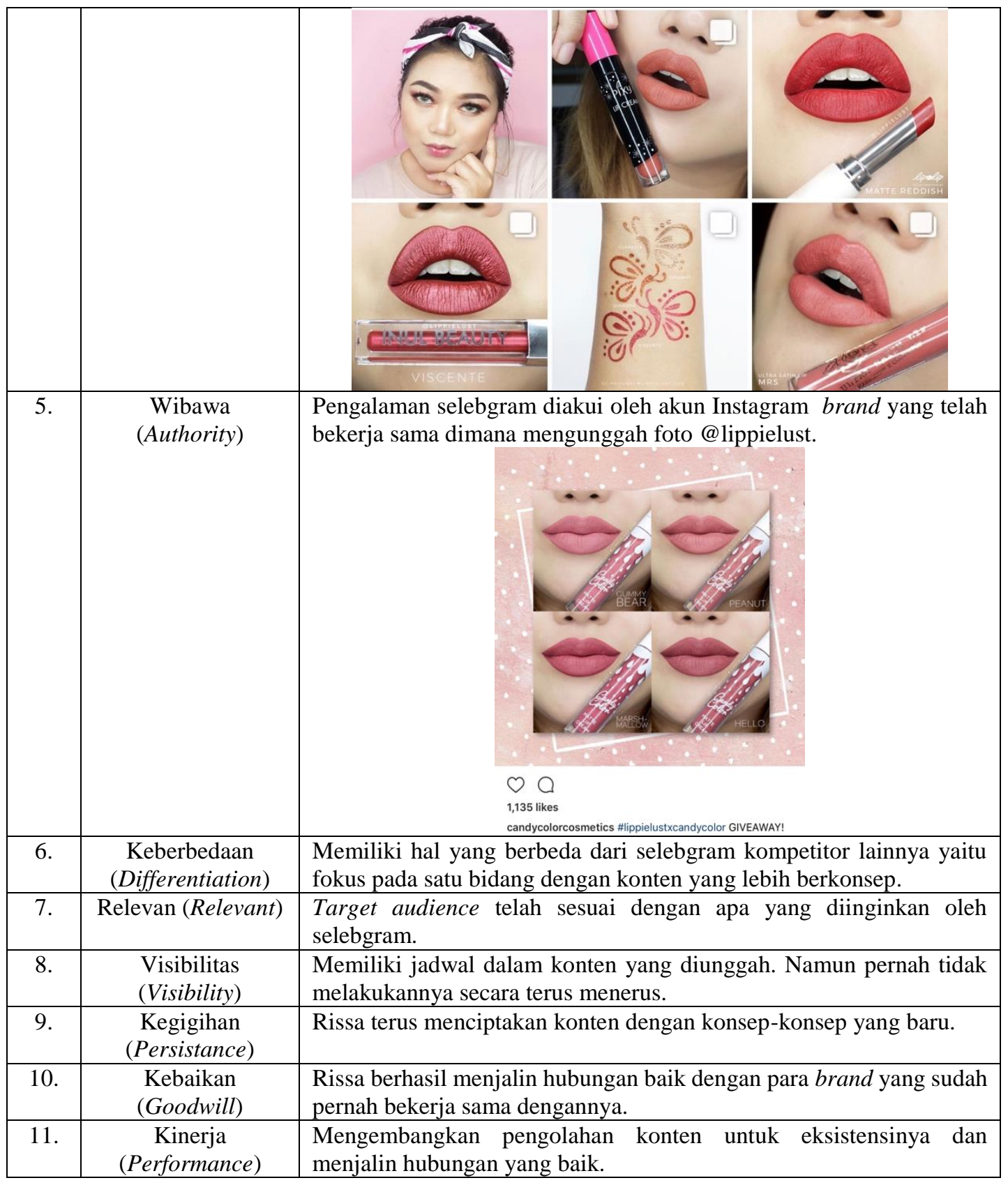

Keotentikan (Authencity). Dalam Personal Branding menurut Rampersad (2008: 19), keotentikan adalah menjadi diri sendiri yang dibangun dengan visi, nilai-nilai, karakter yang dimiliki sendiri yang diselaraskan dengan ambisi pribadi. Individu harus memaparkan keotentikan dirinya yang sebenarnya yang dimulai dengan menentukan ambisi dari pribadi itu sendiri. Berdasarkan kriteria keotentikan oleh Rampersad (2008: 19), peneliti menyimpulkan bahwa Personal Branding yang dilakukan Rissa dalam akun Instagram @lippielust dalam hal visi, nilai-nilai, karakter yang dimiliki sendiri, selaras dengan ambisi pribadi yang ditampilkan.

Integritas (Integrity). Selain keotentikan, dalam melakukan Personal Branding harus memperhatikan kriteria-kriteria lainnya, yang selanjutnya itu adalah integritas. Menurut Rampersad (2008: 19) integritas adalah tentang kode moral yang merupakan penerapan perilaku pelaku terhadap khalayaknya. Peneliti mengambil kesimpulan berdasarkan kriteria Personal Branding integritas menurut Rampersad (2008: 19) bahwa Rissa dalam akun Instagram @lippielust telah melakukan kode moral yang merupakan penerapan perilaku pelaku terhadap khalayaknya. 
Konsisten (Consistency). Konsisten merupakan hal yang diperlukan dalam melakukan Personal Branding, kekonsistenan menurut Rampersad (2008: 19) memerlukan keberanian, konsistensi dapat berupa pesan yang disampaikan secara terus menerus oleh pelaku Personal Branding dalam mengunggah sebuah konten yang sama di media sosial. Selain itu, dapat berupa perilaku yang disampaikan secara terus menerus dan tetap pada jati dirinya sendiri. Hal yang dilakukan Rissa dapat dikatakan konsisten, karena Rissa secara terus menerus menyampaikan pesan dimana perilakunya yang memang tidak berubah hanya pada satu fokus saja dalam akun Instagramnya dalam melakukan Personal Branding.

Spesialisasi (Specialization). Menurut Rampersad (2008: 19) spesialisasi itu hanya berfokus dalam satu bidang bakat atau keterampilan. Dalam melakukan Personal Branding spesialisasi itu perlu untuk menjadikan kita terfokus dengan bidang yang dijalani. Rissa bisa dikatakan terspesialisasi karena kontennya dalam melakukan Personal Branding dalam akun Instagramnya hanya berfokus pada satu bidang saja yaitu beauty yang lebih spesifik lagi ialah lipstick.

Wibawa (Authority). Wibawa atau otoritas dapat menurut Rampersad (2008:19) diakui dalam bidang tertentu dimana diakui sebagai orang yang memang berpengalaman di bidangnya dalam melakukan Personal Branding. Sesuai dengan Rampersad (2008: 19), dengan pemaparan diatas, bahwa Rissa diakui sebagai orang yang ahli dalam bidang tersebut dan merupakan orang yang berpengalaman dalam bidangnya.

Keberbedaan (Differentiation). Berbeda berdasarkan merek dan mempunyai keunikan dalam melakukan Personal Branding merupakan salah satu kriteria Personal Branding dalam poin keberbedaan menurut Rampersad (2008: 19). Bahwa Rissa memiliki keunikan tersendiri yang membedakan dirinya dengan orang lain yaitu memilih konten swatched lipstick dan membuatnya menjadi lebih berkonsep sesuai dengan ciri brand yang bekerja sama dengannya.

Relevan (Relevant). Personal Branding dapat dianggap relevan jika terhubung dengan khalayak yang dianggap penting menurut Rampersad (2008: 19). Terhubung dengan khalayak memiliki artian mempunyai keselarasan antara target khalayak dengan pelaku Personal Branding. Melalui kriteria relevan menurut Rampersad (2008:19), peneliti dapat menyimpulkan bahwa Rissa dengan sukses menjalankan Personal Branding dalam poin relevan dimana target khalayak dengan konten yang diunggah sudah selaras.

Visibilitas (Visibility). Personal Branding yang disiarkan berkali-kali, terus menerus, secara konsisten dan dilakukan berulang kali merupakan Visibilitas menurut kriteria Personal Branding Rampersad (2008:19). Dimana konten harus berkali-kali dilakukan, terus menerus diunggah secara berulang kali. Peneliti menarik kesimpulan bahwa Rissa kurang dalam kriteria Personal Branding visibilitas melalui akun media sosial Instagram, dimana Rissa pernah tidak terus menerus melakukan unggahan pada akun Instagramnya sehingga terpaan followers Rissa tidak selalu langsung naik.

Kegigihan (Persistance). Konsisten pada Personal Branding yang dibentuk, tidak merubah haluan, setia, tidak menyerah, yakin terhadap diri sendiri dan tetap berfokus terhadap satu bidang merupakan kriteria Personal Branding dalam poin kegigihan menurut Rampersad (2008: 20). Brand yang dibentuk harus berkembang secara organik dan memerlukan waktu untuk tumbuh. Melalui kriteria kegigihan menurut Rampersad (2008:20), Rissa berhasil konsisten pada Personal Branding yang dibentuk, tidak merubah haluan, setia, tidak menyerah, yakin terhadap diri sendiri dan tetap berfokus terhadap satu bidang yang dipilih.

Kebaikan (Goodwill). Hubungan baik yang berkaitan dengan hal yang positif dan bermanfaat sehingga akan memberikan hasil baik yang lebih tahan lama merupakan penjelasan dari kriteria poin kebaikan menurut Rampersad (2008:20). Rissa telah sukses menjalin hubungan dengan baik yang berkaitan dengan hal yang positif dan bermanfaat sehingga memberikan hasil baik yang lebih tahan lama.

Kinerja (Performance). Menurut Rampersad (2008:20) kinerja merupakan poin paling penting setelah brand pelaku Personal Branding itu sendiri dikenal. Jika tidak melakukan perbaikan diri akan menjadi sesuatu yang palsu. Rissa melakukan kinerja dengan baik dengan mempunyai kinerja yang terukur dan selalu melakukan perkembangan pada kontennya dalam akun Instagram @lippiekust.

\section{KESIMPULAN}


Rissa hadir dengan akun Instagram @lippielust dengan sebelas kriteria Personal Branding keotentikan, integritas, konsisten, spesialisasi, wibawa, keberbedaan, relevan, visibilitas, kegigihan, kebaikan dan kinerja. Keotentikan, sebagai selebgram yang memiliki ambisi pribadi yang selaras dengan karakter dan merupakan pelopor swatcher lipstick di Indonesia. Integritas memiliki tata perilaku yang baik terhadap khalayaknya. Konsisten, terus menerus dalam menyampaikan pesan dan perilakunya yang memang tidak berubah hanya pada satu fokus saja.

Spesialisasi, konten dalam melakukan Personal Branding dalam akun Instagramnya hanya berfokus pada satu bidang saja yaitu beauty yang lebih spesifik lagi ialah lipstick. Wibawa, bahwa Rissa diakui sebagai orang yang ahli dalam bidang beauty yang lebih spesifik yaitu lipstick dan merupakan orang yang berpengalaman dalam bidangnya sehingga banyak brand yang mengunggah kembali hasil kerjasamanya dengan Rissa. Keberbedaan, Rissa memiliki keunikan tersendiri yang membedakan dirinya dengan orang lain yaitu memilih konten swatched lipstick dan membuatnya menjadi lebih berkonsep sesuai dengan ciri brand yang bekerja sama dengannya. Relevan, target khalayak yang diinginkan dengan konten yang diunggah sudah selaras. Visibilitas, memiliki jadwal dalam unggahan konten, namun pernah tidak terus menerus melakukan unggahan pada akun Instagramnya.

Kegigihan, tidak merubah haluan, setia, tidak menyerah, yakin terhadap diri sendiri dan tetap berfokus terhadap satu bidang yang dipilih yaitu beauty. Kebaikan, dimana Rissa sukses menjalin hubungan dengan baik dengan banyak brand. Kinerja, dilakukannya dengan baik yang dibarengi oleh kinerja yang terukur dan selalu melakukan perkembangan pada kontennya dalam akun Instagram @lippiekust. Namun, Rissa pernah tidak mengunggah secara terus-menerus dan berkali-kali kontennya dalam akun Instagramnya saat Rissa merasa jenuh dimana kurang sesuai pada sisi visibilitas.

\section{Daftar Pustaka}

Aaker, David. 2014. Aaker On Branding. Jakarta: PT. Gramedia Pustaka Utama.

Dyah, Andina. 2014. Studi Elaboration Likehood Model pada Pengaruh Selebgram (Selebriti Endorser Instagram) terhadap Minat Pembelian dalam Media Sosial Instagram. https://www.academia.edu/8370228/jurnal_all. diakses $15 \quad$ Oktober 2017, Pukul 20.18)

Farhat, Rhesma \& Khan, Bilal Mustafa. 2011. Celebrity Endorsement: A Congruity Measure of Personalities. Vol.1, No.1. http://iiste.org, diakses 15 Oktober 2017, Pukul 18.14)

Gane, Nicholas \& Beer, David. 2008. New Media: The Key Concepts. USA: Berg.

Montoya, Peter. 2002. The Personal Branding Phenomenon. Nashville: Vaughan Printing.

Mulyana, Deddy. 2008. Pengantar Ilmu Komunikasi. 2002. Bandung: PT RemajaRosdakarya.

Rampersad. Hubert K. 2008. Authentic Personal Branding. Jakarta: PPM Publishing.

Salpeter, Miriam. Social Networking for Career Success: Using Online Tools to Create a Personal Brand. (e-book) http://en.bookfi.net/s/?q=online+media\&t=0. Diakses 20 Oktober 2017.

Suryani, Tatik. 2013. Perilaku Konsumen di Era Internet: Implikasi pada Strategi Pemasaran. Yogyakarta: Graha Ilmu. 